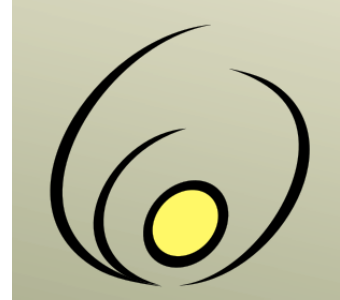

Fórum de Pró-Reitores de Extensão das Instituições Públicas de

Educação Superior Brasileiras

\section{Revista Brasileira de Extensão Universitária}

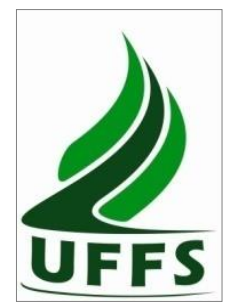

v. 12 , n. 1, p. 23-32, jan.-abr. 2021

e-ISSN 2358-0399

\title{
Dança circular em maternidade: Vivência extensionista
}

\author{
Ellen Reiner da Silva Santos ${ }^{1}$, Geisiane de Almeida Mendonça ${ }^{2}$, Zannety Conceição Silva do \\ Nascimento Souza ${ }^{3}$, Ariane Cedraz Morais ${ }^{4}$, Amanda Leite Novaes ${ }^{5}$
}

\begin{abstract}
Resumo: A Dança Circular é uma prática corporal na qual as pessoas compõem um círculo e dançam juntas, buscando a integração humana na roda através do seu canto, ritmo e execução, a fim de promover o equilíbrio, bem estar físico, mental e social, integrando hoje uma das propostas de implementação das Práticas Integrativas e Complementares em Saúde (PICS) no Sistema Único de Saúde (SUS). O objetivo geral desse artigo é descrever a experiência de promoção da saúde de gestantes, parturientes e puérperas internadas em maternidade através da Dança Circular, por meio das ações extensionistas. Trata-se de um relato de experiência em uma maternidade pública no interior da Bahia, que aborda o desenvolvimento de quatro sessões de Dança Circular, com duração média de 15 minutos cada uma, com a participação de 6 gestantes, 8 puérperas, 6 acompanhantes, 1 profissional de saúde e 1 graduanda em Psicologia; os momentos foram conduzidos por 2 professoras (Enfermeiras Obstetras) e 5 discentes do curso de graduação em Enfermagem, com treinamento prévio na técnica da Dança. Durante a realização das sessões, os participantes mostraram-se sorridentes, alegres e receptivos, sentimentos esses que foram comprovados nos relatos escritos nas fichas de avaliação. As sessões de Dança Circular foram realizadas em mais de um local dentro da maternidade, com a participação de diferentes públicos em cada sessão. Foi possível perceber que a Dança Circular impactou positivamente no bem-estar das participantes.
\end{abstract}

Palavras-chave: Terapias Complementares; Enfermagem Obstétrica; Relações Comunidade-Instituição

\section{Pharmaceutical care in social institutions: extension as a strategy for learning and health promotion}

Abstract: Circular Dance is a corporal practice in which people form a circle and dance together, seeking human integration in the circle through their singing, rhythm, and execution, in order to promote balance, physical, mental and social well-being, integrating today one of the proposals for the implementation of Integrative and Complementary Practices in Health (PICS) in the Unified Health System (SUS). The general objective of this article was to describe the health promotion experience of pregnant women, parturients, and puerperal women admitted to maternity through Circular Dance, through extension actions. It is an experience report in a public maternity hospital in the countryside of Bahia State, which addresses the development of four Circular Dance sessions. The sessions had an average duration of 15 minutes each, with the participation of 6 pregnant women, 8 puerperal women, 6 companions, 1 health professional, and 1 undergraduate student in Psychology; the moments were conducted by 2 instructors (Obstetric Nurses) and 5 students of the undergraduate nursing course, with previous training in the dance technique. During the sessions, the participants were smiling, happy and receptive, feelings that were confirmed in the reports written in the evaluation forms. The Circular Dance sessions were held in more than one place within the maternity ward, with the participation of different audiences in each session. It was possible to notice that the Circular Dance had a positive impact on the well-being of the participants.

Keywords: Complementary Therapies; Obstetric Nursing; Community-Institutional Relations

\section{Originais recebidos em}

29 de julho de 2020

Aceito para publicação em

21 de dezembro de 2020

1

Graduanda em Enfermagem pela Universidade Estadual de Feira de Santana (UEFS), Bahia, Brasil

(autora para correspondência)

ellenreiner1@gmail.com

2

Graduanda em Enfermagem pela Universidade Estadual de Feira de Santana (UEFS)

3

Universidade Estadual de Feira de Santana (UEFS)

https://orcid.org/0000-0002-4573-525X

4

Universidade Estadual de Feira de Santana (UEFS)

https://orcid.org/0000-0001-9445-4596

5

Universidade Estadual de Feira de Santana (UEFS)

https://orcid.org/0000-0002-2427-8248 


\section{Introdução}

O ser humano sempre utilizou estratégias para poder expressar seus sentimentos e emoções, e a dança, de um modo geral, representa uma delas. A Dança Circular, especificamente - antes conhecida como Dança Circular Sagrada - iniciou-se com o coreógrafo Polonês Bernhard Wosien em 1976, na Fundação Findhorn, diante do seu interesse por danças tradicionais e por enxergar na Dança Circular a simplicidade do ritmo e execução, podendo ser trabalhada em grupo (Barton, 2012).

Em relação à dança, geralmente as pessoas ficam com as mãos dadas, na qual a palma da mão direita fica para cima e a da mão esquerda vira-se para baixo, tendo em vista representar a retro-ligação e o passar a luz adiante entre participantes, interligando presente e passado sob o que é eterno, a partir da simbologia do círculo (Wosien, 2000). Tratam-se de simbologias que identificam a Dança Circular e, dessa forma, as experiências tecidas na vida, por cada pessoa, são partilhadas na roda pelo movimento.

Segundo o Ministério da Saúde (2018), a Dança Circular é uma prática corporal na qual as pessoas compõem um círculo e dançam juntas, buscando a integração humana na roda através do seu canto, ritmo e execução, a fim de promover o equilíbrio, bem estar físico, mental e social, integrando hoje uma das propostas de implementação das Práticas Integrativas e Complementares em Saúde (PICS) no Sistema Único de Saúde (SUS).

As PICS foram institucionalizadas no SUS através da Política Nacional de Práticas Integrativas e Complementares em Saúde (PNPIC) - aprovada por meio da Portaria GM/ MS nº 971, de 3 de maio de 2006, tendo sua construção influenciada pelas conferências nacionais de saúde e Organização Mundial da Saúde (OMS). A PNPIC tem como objetivo ampliar e diversificar os recursos terapêuticos fornecidos pelo SUS, visando à promoção da saúde e prevenção de agravos na perspectiva de um cuidado integral e humanizado. Dessa forma, em março de 2017, a PNPIC ampliou suas modalidades, incluindo a Dança Circular como uma das propostas das PICS, somada às outras práticas, tais como Arteterapia, Musicoterapia, Biodança, Meditação, Reiki, Yoga, entre outras (Ministério da Saúde, 2015, 2017).

Partindo-se da perspectiva de um cuidado integral e humanizado, as PICS podem ser realizadas em todos os campos de atenção à saúde. Um desses campos é a maternidade, unidade na qual é possível utilizar as PICS, incluindo a Dança Circular como uma estratégia para a promoção de boas práticas de cuidado à mulher e seus familiares no trabalho de parto e parto.

Em relação às boas práticas, a assistência à mulher durante o trabalho de parto e parto tem passado por muitas mudanças e atualizações, com o intuito de promover esse cuidado humanizado às parturientes. Com o objetivo de estabelecer a padronização do cuidado pelos profissionais, diminuir as intervenções desnecessárias durante o trabalho de parto e parto, o Ministério da Saúde (2017) elaborou as Diretrizes Nacionais de Assistência ao Parto Normal, que foi aprovada e publicada em 14 de fevereiro de 2017.

Estas diretrizes incluem boas práticas de cuidado, caracterizadas por ações que têm como objetivo contribuir para a evolução do trabalho de parto e parto, promovendo o alívio da dor a partir de métodos não farmacológicos; além disso, reforçam o direito de escolha e liberdade da parturiente, favorecendo o protagonismo da mulher durante o trabalho de parto e parto, partindo-se também da perspectiva da humanização do cuidado. Dentre as recomendações propostas pelo Ministério da Saúde estão: o direito ao acompanhante, a oferta de líquidos claros durante o trabalho de parto, uso de métodos não farmacológicos para o alívio da dor, banho morno, musicoterapia, liberdade de movimentação, aromaterapia, o incentivo à adoção da posição verticalizada, entre outros (Ministério da Saúde, 2017).

Falando em liberdade de movimentação no trabalho de parto, como a Dança Circular envolve movimentos para a sua execução, poderá ser adaptada às gestantes com a realização de movimentos pélvicos. A pelve é 
uma estrutura que está intimamente ligada à mecânica do parto e sua movimentação contribui, consequentemente, para a evolução do trabalho de parto, configurando-se como uma estratégia na realização de boas práticas nesse período (Boaviagem et al., 2019).

A formação profissional da enfermeira para realização destas boas práticas se inicia desde a graduação por meio do envolvimento discente em atividades de ensino, pesquisa e extensão. Nessa perspectiva, foi criado um programa de extensão universitária intitulado 'Acolhendo e Humanizando Partos e Nascimentos', vinculado ao Núcleo de Extensão e Pesquisa em Saúde da Mulher (NEPEM) da Universidade Estadual de Feira de Santana na Bahia, que tem por um dos objetivos específicos: fortalecer as boas práticas preconizadas pelo Ministério da Saúde e, assim, proporcionar mais qualidade aos serviços prestados para a comunidade.

Entre os planos de trabalho vinculados a este programa de extensão universitária está inserida a proposta de Dança Circular com gestantes internadas em maternidade: promoção do bem-estar com ações extensionistas. Foi a partir do desenvolvimento das ações extensionistas desse plano de trabalho que emergiu a experiência que será descrita e analisada neste artigo.

Diante do exposto, o objetivo geral desse artigo é descrever a experiência de promoção da saúde de gestantes, parturientes e puérperas internadas em maternidade através da Dança Circular, por meio das ações extensionistas.

\section{Procedimentos Metodológicos}

Trata-se de um relato de experiência, ou seja, "uma construção teórico-prática que se propõe ao refinamento de saberes sobre a experiência em si, a partir do olhar do sujeito pesquisador em um determinado contexto cultural e histórico" (Daltro \& Faria, 2019, p. 228).

A experiência foi realizada em uma maternidade pública no interior da Bahia por bolsistas de extensão universitária. Esta maternidade atende as demandas das zonas rural e urbana da região em que se localiza. Quando a equipe do programa de extensão realizou a visita para ambientação e programação das atividades, observou-se que os setores que estavam aptos a receberem as ações propostas pelo plano de trabalho, sem prejuízo à rotina do serviço, e com espaço que permitia o uso de som em baixo volume e a realização dos passos de dança, eram: centro obstétrico, casa da puérpera e enfermaria para gestação de alto risco. Além disso, vale ressaltar que a equipe que compõe o atendimento da unidade mostrou-se receptiva e colaborativa às ações desenvolvidas pelas bolsistas de extensão.

Estas ações são inerentes às propostas do plano de trabalho intitulado "Dança Circular com gestantes internadas em maternidade: promoção do bem-estar com ações extensionistas" vinculado ao programa de extensão "Acolhendo e Humanizando Partos e Nascimentos".

O Programa de Extensão deu início em 2018, composto por cinco bolsistas e sob orientação de duas professoras e enfermeiras obstetras. Os planos de trabalho são produzidos e desenvolvidos individualmente por cada aluno bolsista, aprovados por uma comissão institucional da universidade, com anuência dos profissionais da maternidade. Os bolsistas executam seus planos de trabalhos na perspectiva de boas práticas e cuidado humanizado, que envolvem ações como uso de massagens para relaxamento e alívio da dor, ambiência, uso do plano de parto, educação permanente e Dança Circular.

A população-alvo do plano de trabalho sobre Dança Circular foi composta por gestantes em trabalho de parto e parto no centro obstétrico, gestantes de alto risco internadas na enfermaria e puérperas; a equipe de Enfermagem do centro obstétrico e setor de triagem (Acolhimento e Classificação de Risco) poderia participar 
da atividade mesmo não sendo o público-alvo, para interação e relaxamento. Nesse sentido, uma profissional de saúde participou de uma sessão.

Além disso, este Programa de Extensão conta com o suporte de recurso material e financeiro da Pró-Reitoria de Extensão (PROEX) da Universidade Estadual de Feira de Santana e apoio do NEPEM.

O plano de trabalho sobre Dança Circular, cuja experiência será descrita neste artigo, foi elaborado e desenvolvido por uma discente bolsista e graduanda em Enfermagem, com o apoio de outros integrantes do programa de extensão, visto que há interação entre as atividades propostas pelos diferentes planos. A discente responsável pelo plano de trabalho integrou um grupo de estudo sobre Dança Circular com docentes e discentes da área de Educação Física e Psicologia, para a melhor compreensão e aplicação da técnica da Dança Circular. Além disso, as bolsistas estudaram materiais e vídeos disponibilizados na internet que demonstraram as técnicas da Dança Circular, para o aperfeiçoamento do conhecimento acerca da temática e treinamento.

As ações extensionistas foram desenvolvidas no centro obstétrico, enfermaria para gestantes de risco e casa da puérpera da maternidade, contando com a presença de bolsistas de extensão, docentes, funcionários, gestantes e familiares. Estes setores foram escolhidos por acolherem mulheres com necessidade de relaxamento e conforto diante das contrações dolorosas, estresse e ansiedade provenientes da hospitalização e/ou gestação de risco.

Nesse sentido, antes da realização da dança, avaliava-se o prontuário e informações complementares junto à equipe de Enfermagem, para que nenhuma atividade conflitasse com alguma prescrição médica, em especial com o tipo de repouso.

Entre os meses de agosto a dezembro de 2019, foram realizadas quatro sessões de Dança Circular, com duração média de 15 minutos cada uma, com a participação de 6 gestantes, 8 puérperas, 6 acompanhantes, 1 profissional de saúde e 1 graduanda em Psicologia; os momentos foram conduzidos por 2 professoras (Enfermeiras Obstétricas) e 5 discentes do curso de graduação em Enfermagem, com treinamento prévio na técnica da Dança, totalizando vinte e nove pessoas envolvidas, incluindo discentes e docentes, com uma média de cinco gestantes e/ou puérperas por sessão.

Para a realização da Dança Circular as bolsistas, em média três por sessão, organizavam o local com a supervisão da professora, reuniam as (os) participantes das sessões, faziam uma breve explicação a respeito da temática, promovendo um momento de integração, apresentando as músicas, os passos e orientando-os a formarem uma roda.

As sessões foram realizadas a partir de uma programação prévia feita pelas bolsistas. As músicas e passos foram escolhidos e adaptados ao público que iria participar das atividades, com características regionais, mas seguindo as orientações da teoria da Dança Circular.

Quando as sessões eram para gestantes no trabalho de parto e com quadro clínico estável, por exemplo, utilizavam-se músicas que abordassem em sua letra o vínculo de mãe e filho, com ritmo suave. No entanto, necessitava-se de um cuidado maior na escolha das músicas para um público emocionalmente mais instável como puérperas com filhos internados na UTI, e quando as gestantes estavam internadas na enfermaria por alguma complicação obstétrica. O acompanhamento das reações físicas e emocionais das gestantes participantes era feito de forma criteriosa pela professora Enfermeira que estivesse supervisionando a atividade do dia, para que se houvesse necessidade fosse acionada a equipe de psicologia da unidade.

A fim de promover a ambiência necessária para a realização da dança e execução das atividades, as bolsistas levavam alguns recursos, tais como caixa de som portátil, fichas para enquete da avaliação da atividade sem identificação dos participantes, respeitando os princípios éticos, com o objetivo de se conhecer os pontos 
positivos e a melhorar, relacionados à dinâmica utilizada, além de folhas em branco para expressão de sentimentos.

Sobre as fichas de avaliação da atividade, estas foram identificadas com a sigla que representava o ser participante (Part.), e algumas das opiniões estarão descritas na parte de Resultados. Por se tratar de uma enquete avaliativa da atividade extensionista, sem o uso de informações que pudessem identificar os participantes, não houve envio prévio ao Comitê de Ética em Pesquisa com Seres Humanos.

O setor de Educação Permanente e a diretoria da maternidade autorizaram as atividades extensionistas, que são institucionalizadas formalmente na universidade.

\section{Resultados}

As sessões de Dança Circular foram realizadas em mais de um local dentro da maternidade, com a participação de diferentes públicos em cada sessão, o que levou à necessidade de adaptar os passos para os participantes, tendo em vista as especificidades do ambiente e quadros clínicos.

A primeira sessão foi realizada na enfermaria destinada às gestantes de risco (Figura 1). O uso das PICS com mulheres internadas em ambiente hospitalar, sobretudo aquelas que apresentavam gestação de risco, necessitou de uma avaliação criteriosa sobre as repercussões das atividades no quadro clínico da parturiente. Logo, a dança só foi realizada com as participantes quando sua condição clínica permitia e com anuência da equipe de cuidados do plantão.

As discentes se sensibilizaram e convidaram uma funcionária que estava gestante para participar da sessão, proporcionando no seu ambiente de trabalho, um momento de relaxamento e distração.

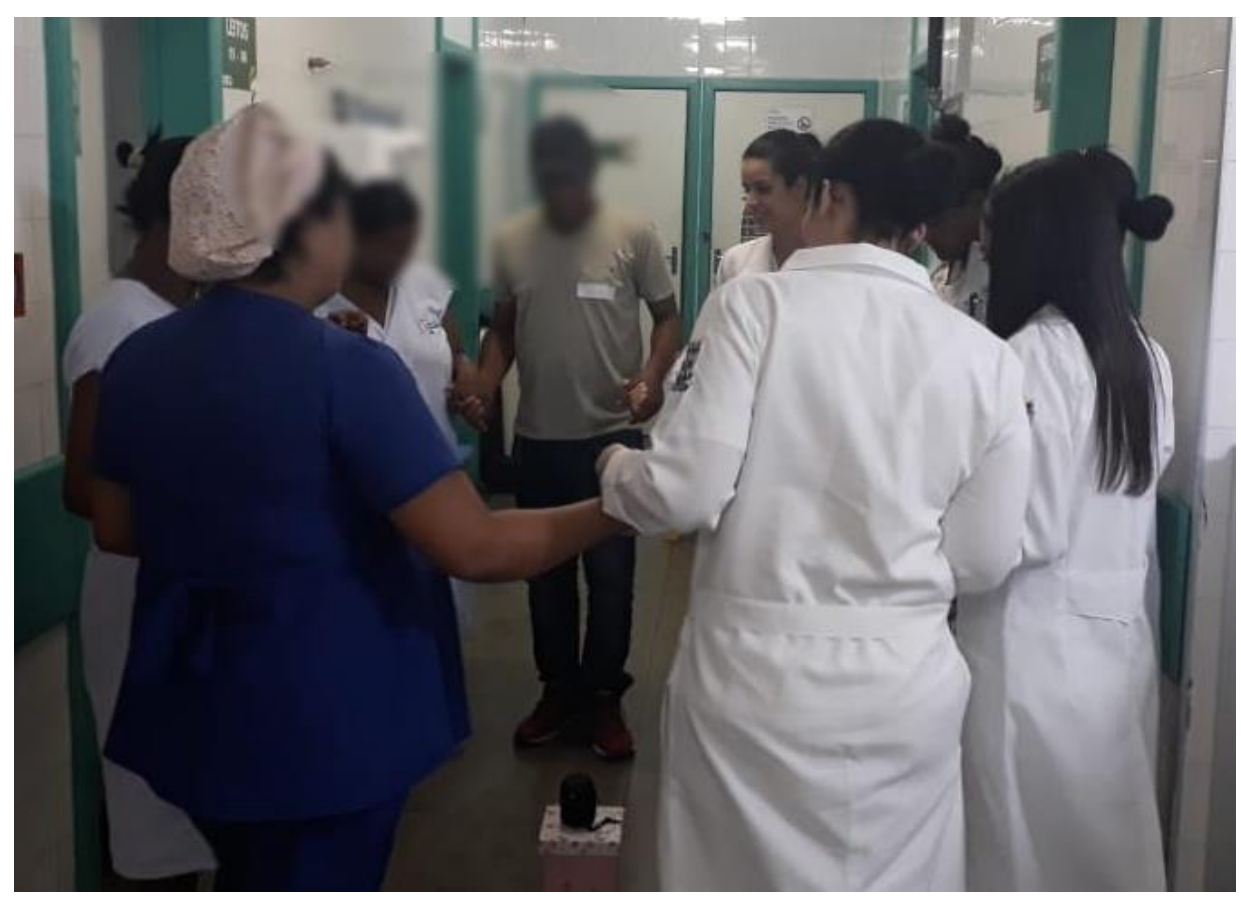

Figura 1. Sessão de dança circular realizada na enfermaria destinada às gestantes de risco. 
A segunda sessão foi realizada na casa da puérpera, um setor que a maternidade possui para hospedar as mulheres que têm seus bebês internados no berçário ou na UTI (Figura 2).

A terceira sessão foi realizada no centro obstétrico, com parturientes em trabalho de parto (Figura 3). Como a Dança Circular envolve movimentos, foi possível adaptar os passos de forma que ajudassem na evolução do trabalho de parto das gestantes, e promovessem a conexão ainda maior da mãe com o feto.

Durante a realização das sessões, os participantes mostraram-se sorridentes, alegres e receptivos. Tais sentimentos foram comprovados nos relatos escritos na folha de expressão de sentimentos e nas fichas de avaliação, sendo que as últimas tiveram como propósito avaliar a percepção dos participantes sobre a realização da Dança Circular, benefícios promovidos e sugestões para incentivar melhorias para as sessões futuras.

Muito bom e importante. Estava com a mente pesada e agora está levinha. Voltem mais vezes e não se esqueçam da gente. (Part. 02)

O estresse promovido pelo ambiente hospitalar e tempo de internação era perceptível na expressão facial dos participantes no momento que antecedia a dança. Um dos relatos foi de um pai e acompanhante que expressou, na ficha de sentimentos positivos para a internação, o desejo que o nascimento da filha transcorresse bem, frente à gestação de risco da companheira internada, e em conversa sobre o escrito na ficha, manifestou a tensão e ansiedade pelo tempo de internação da esposa.

Muito amor, paz e que Deus ajude a nossa filha a vir com muita saúde. (Part. 04)

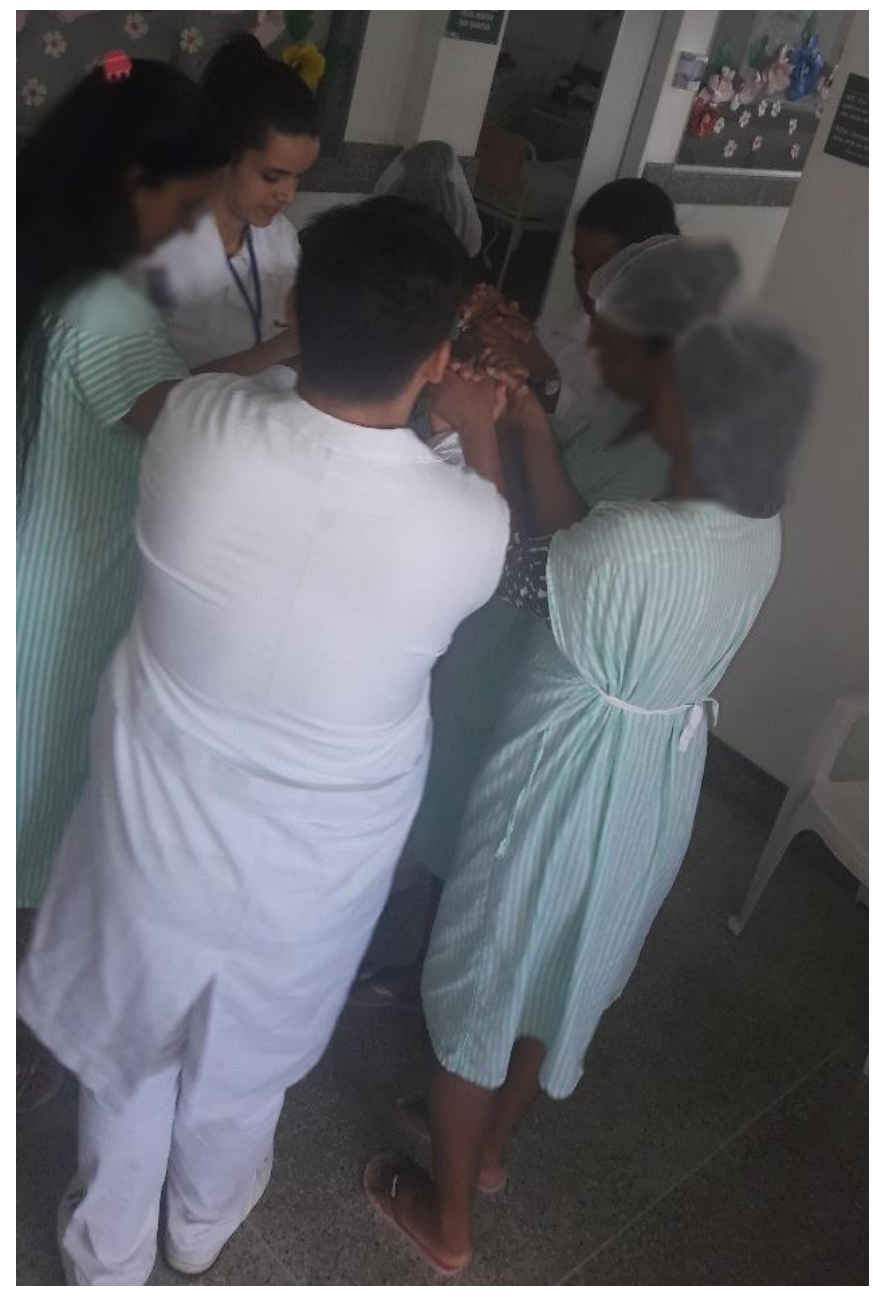

Figura 2. Sessão na casa da puérpera, setor da maternidade destinado às mulheres que têm seus bebês internados no berçário ou na UTI. 


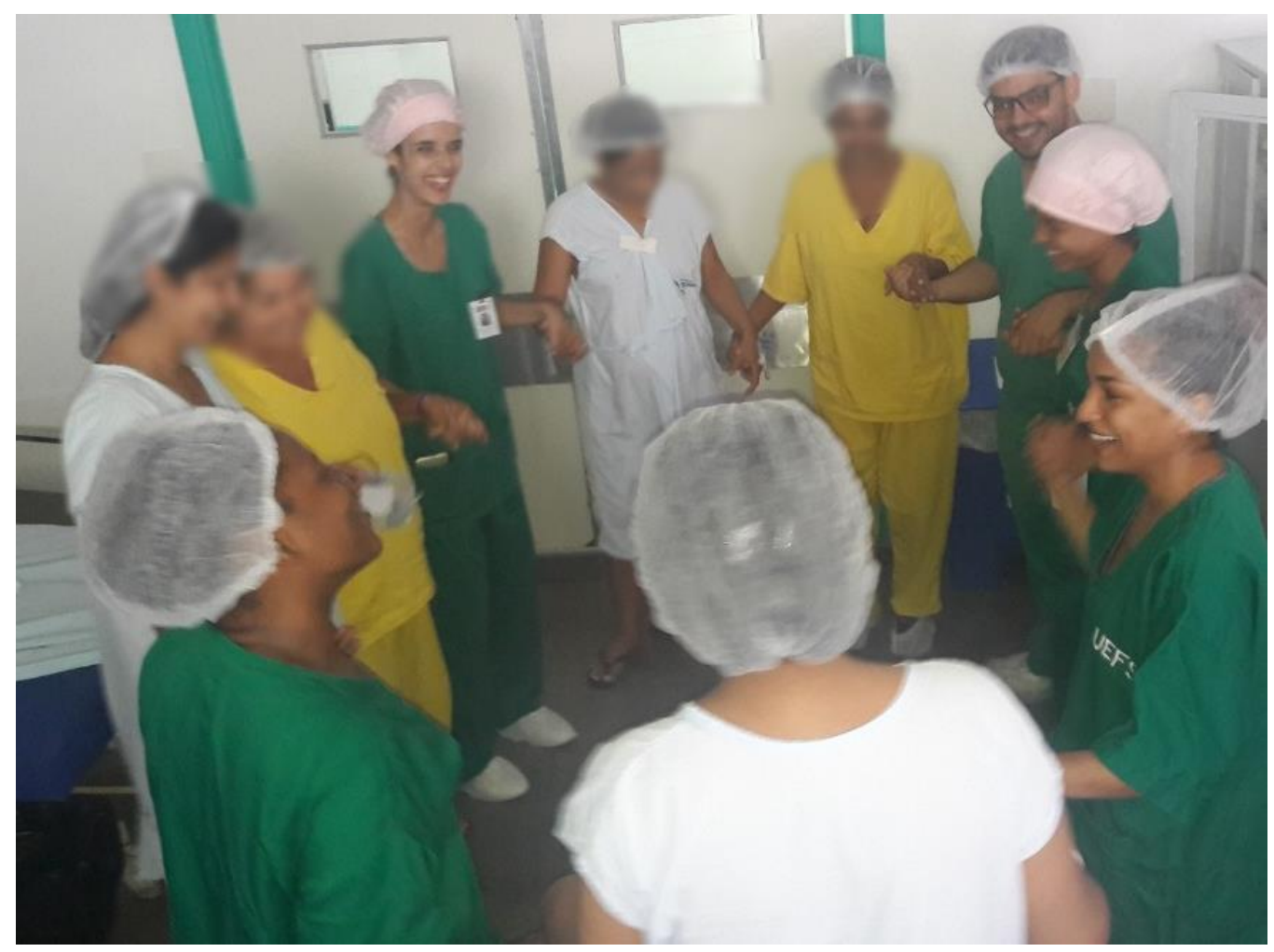

Figura 3. Sessão realizada na sala de parto no centro obstétrico.

Durante a sessão, percebeu-se o envolvimento afetivo entre este acompanhante e sua esposa, e entre os demais participantes, o que ratifica a troca de energia entre o grupo durante as sessões. Ao final da sessão, o mesmo acompanhante relatou que o momento de integração da dança foi muito importante, passando alegria e tranquilidade para eles.

Em outro relato, uma gestante de risco e sua acompanhante (mãe) relataram que o momento proporcionou alegria e foi muito significativo para ambas.

Eu adorei! Meu coração está cheio de paz e luz, e sinto mais forte, minha fé só fez crescer mais. (Part. 05)

Achei muito bom, maravilhoso! Andar com fé eu vou. (Part. 01)

O relato da mãe e acompanhante reforçou a proposta de relaxamento e demais benefícios promovidos pela Dança Circular; as participantes referiram aspectos relacionados à fé naquele momento, a partir da letra da música utilizada, demonstrando como a estratégia pode fortalecer o conforto durante o período de internação.

De um modo geral, os participantes externaram nas fichas sentimentos de leveza, alegria, tranquilidade e relaxamento após a dança. A partir dos registros, expressão facial e relato verbal dos participantes, foi possível perceber que a Dança Circular impactou positivamente no bem-estar dos mesmos.

Amei a apresentação! Isso nos fez sentir mais leves nesta tarde. Que vocês continuem levando essa alegria contagiante sempre para as pessoas. (Part. 03)

Uma participante experimentou a dança duas vezes, em momentos distintos. A primeira vez foi durante seu trabalho de parto e a segunda vez na casa da puérpera, já que seu bebê precisou de suporte contínuo em UTI, pois havia nascido prematuro. 
Na primeira experiência com a Dança Circular, a gestante se encontrava em trabalho de parto prematuro, no centro obstétrico, com contrações e acompanhada de familiar. Durante a sessão, percebeu-se a imersão da gestante no trabalho de parto e o suporte afetivo da acompanhante. A parturiente executou os passos da dança, com ênfase em movimentos pélvicos, de modo a auxiliar na evolução do seu parto, o qual aconteceu no mesmo dia.

No segundo momento, a mãe se encontrava na casa da puérpera, pois seu bebê ficou internado durante alguns dias na UTI. De início, ela ficou muito contente em rever a equipe do programa de extensão, e por ter a oportunidade de participar novamente da dança, e referiu o benefício da vivência, como veremos na fala a seguir:

Um bom momento para distrair de toda tensão, relaxar e ajudar a descontrair. Continuem sendo as profissionais tão maravilhosas que são e muito obrigada por toda atenção. (Part. 06)

Após a sessão ela relatou que na primeira experiência ela não aproveitou tanto como na segunda, devido ao contexto que ela se encontrava, com as dores das contrações. Já na última sessão ela descreveu que foi um momento único, se emocionou, recebeu um suporte emocional da equipe e no término da programação ela teve a notícia da alta do seu bebê.

\section{Discussão}

As boas práticas na unidade obstétrica permitem ampliar o processo do cuidado para além das práticas tecnicistas. A utilização dessas juntamente com o envolvimento da equipe multidisciplinar podem contribuir para a melhoria do cenário obstétrico, sobretudo na atenção à mulher durante o trabalho de parto e parto (Pereira et al., 2018).

No período gravídico-puerperal, a mulher desfruta de diferentes sentimentos, havendo diversos fatores que os influenciam. Oliveira e Mandú (2015), durante o seu estudo com 12 mulheres, perceberam que ambas relataram o sentimento de alegria e satisfação de ter um filho, porém, ao mesmo tempo elas revelaram ter medo e insegurança. Quando se trata de gestação de risco, o estado emocional das gestantes fica mais sensível por ter o risco de comprometimento da saúde do seu bebê. Portanto, é necessário promover o cuidado, focando no seu bem estar físico e principalmente psicológico, podendo utilizar-se a Dança Circular como uma boa prática de cuidado.

Escolheu-se realizar a Dança Circular na maternidade pública por entender que a unidade é um local que necessita intensificar as boas práticas e humanização do cuidado, a fim de contribuir para a qualidade da assistência e promoção do bem-estar materno-infantil, uma vez que a Dança Circular constitui uma opção de prática integrativa a ser realizada, considerando seus benefícios.

Foi possível perceber que a Dança Circular impactou positivamente no bem-estar das participantes; a dança, o toque, e esse ato de dar as mãos ultrapassaram um simples movimento em roda, acontecendo uma troca de energia entre as pessoas. Andrada e Souza (2015, p. 360) destacaram que "as danças circulares têm o potencial para se tornar um recurso importante no contexto grupal, uma vez que despertam o respeito ao outro, a integração, a inclusão e o acolhimento às adversidades e estimulam a cooperação".

A dança mexe com o emocional, desenvolve o afeto (Andrada \& Souza, 2015) e pode ser utilizada como estratégia de cuidado à gestante como um todo em diversas fases do período gravídico-puerperal.

Segundo Mazzo e Brito (2015), as mulheres no período do puerpério têm necessidades humanas psicobiológicas, psicossociais e psicoespirituais. Portanto, a Dança Circular vai ajudar essas mulheres no enfrentamento das condições psicológicas causadas pelo internamento dos seus bebês. 
Uma vez que a profissão de Enfermagem tem como essência a arte de cuidar (Queirós et al., 2016) vale ressaltar a importância de cuidar das pessoas que cuidam. Nem sempre os profissionais de saúde recebem os cuidados com a visão holística, no ambiente de trabalho. Portanto, "compreende-se que alguns elementos são essenciais para a manutenção desse ambiente saudável" (Barros \& Rodrigues, 2016, p.15).

Por ser a Dança Circular uma prática pouco usual e conhecida, durante o convite para a participação das sessões, algumas pessoas tiveram resistência em aceitar; porém, após ser explicada como seria a sessão, alguns tiveram a curiosidade e decidiram participar. Como já registrado por Wosien (2000, p. 28) "... a dança é, ainda hoje, pedido e oração. Nela, o homem consegue exteriorizar todos os atos primevos da alma, desde o medo até a entrega libertadora" e, assim, percebemos a potência dessa prática para sensibilização, acolhimento, autoconhecimento e expressão humana.

A escolha da maternidade para executar a dança foi pensada com intuito de promover o cuidado diferencial tanto para gestantes, parturientes e puérperas, quanto para os acompanhantes e a própria equipe de profissionais. Contudo, por se tratar de um ambiente hospitalar, houve dificuldades relacionadas à estrutura física do local e ao barulho do ambiente, a exemplo do centro obstétrico, que é um lugar que aloja mais de uma gestante em trabalho de parto, conta com um fluxo maior de profissionais de saúde, e uma estrutura física que pouco favorece a realização da Dança Circular, por ser um setor fechado com equipamentos e instrumentos que restringem a circulação (camas para parto, armários de insumos, mesas auxiliares para procedimentos, cadeiras para acompanhantes e objetos para manejo do parto humanizado).

\section{Considerações Finais}

A experiência extensionista que deu origem a esse estudo demonstrou que é possível promover a saúde de parturientes e puérperas por meio da Dança Circular em maternidade. A Dança Circular mostrou-se, enquanto prática integrativa, como uma boa estratégia de cuidado, de forma humanizada, capaz de promover o bemestar, integração, relaxamento, benefícios físicos, espirituais e psicológicos para gestantes, puérperas, acompanhantes, profissionais, discentes e docentes.

Para a complementação e desenvolvimento das ações foi importante a interdisciplinaridade docente no programa de extensão, considerando a presença de professores da área de Enfermagem e Educação Física, ampliando e agregando os conhecimentos específicos na formação teórico-prática dos discentes envolvidos.

Percebe-se que é essencial o papel da extensão universitária para fortalecer o elo comunidade-universidade, bem como para a formação das discentes. Nessa perspectiva, a experiência da Dança Circular com gestantes hospitalizadas, para além dos benefícios citados, possibilitou o crescimento acadêmico e reflexão para todos que desfrutaram dessa vivência.

\section{Agradecimento}

Nosso agradecimento à Pró-Reitoria de Extensão da Universidade Estadual de Feira de Santana do Estado da Bahia pelo incentivo e apoio logístico ao programa de extensão 'Acolhendo e Humanizando Partos e Nascimentos', e às discentes bolsistas de extensão. Agradecemos também à maternidade parceira do programa de extensão pelo acolhimento e confiança no desenvolvimento das ações extensionistas.

\section{Contribuição de cada autor}

As autoras E.R.S.S., G.A.M. e Z.C.S.N.S. planejaram e escreveram a versão inicial deste artigo, bem como executaram as ações extensionistas descritas na experiência. A autora A.C.M. coordena o programa de 
extensão, participou da redação do artigo e de sua revisão intelectual crítica. A co-autora A.L.N. coordenou o grupo de estudos no qual a autora E.R.S.S. aprofundou a teoria da Dança Circular, participou da redação do artigo e de sua revisão intelectual crítica. Todas as autoras tem responsabilidade pela aprovação final do artigo para publicação.

\section{Referências}

Andrada, P. C. de, \& Souza, V. L. T. de. (2015). Corpo e docência: A dança circular como promotora do desenvolvimento da consciência. Psicologia Escolar e Educacional, 19(2), 359-368.

Barros, A. R. de, \& Rodrigues, L. M. (2016). O exercício profissional de enfermagem e as principais causas de adoecimento laboral: Uma revisão integrativa. Revista Recien - Revista Científica de Enfermagem, 6(18), $12-25$.

Barton, A. (2012). Danças circulares: Dançando o Caminho Sagrado. (Vol. 1, 2. ed.). São Paulo: Triom.

Boaviagem, A., Coutinho, T. A., Oliveira, L. G. A. de, \& Moretti, E. (2019). Comportamento biomecânico da pelve nas diferentes posturas adotadas durante o segundo período do trabalho de parto. Revista Eletrônica da Estácio Recife, 5(1), Article 1.

Daltro, M. R., \& Faria, A. A. de. (2019). Relato de experiência: Uma narrativa científica na pós-modernidade. Estudos e Pesquisas em Psicologia, 19(1), 223-237.

Mazzo, M. H. S. da N., \& Brito, R. S. (2016). Instrumento para consulta de enfermagem à puérpera na atenção básica. Revista Brasileira de Enfermagem, 69(2), 294-303.

Ministério da Saúde. (2015). Política nacional de práticas integrativas e complementares no SUS: Atitude de ampliação de acesso. 2. ed. Brasília: Ministério da Saúde, Secretaria de Atenção à Saúde, Departamento de Atenção Básica. Recuperado de http://bvsms.saude.gov.br/bvs/publicacoes/politica nacional praticas integrativas complementares 2ed.pdf

Ministério da Saúde. (2017). Diretrizes nacionais de assistência ao parto normal: Versão resumida. Brasília: Ministério da Saúde, Secretaria de Ciência, Tecnologia e Insumos Estratégicos, Departamento de Gestão e Incorporação de Tecnologias em Saúde. Recuperado de http://bvsms.saude.gov.br/bvs/publicacoes/ diretrizes nacionais assistencia parto normal.pdf

Ministério da Saúde. (2018). Política nacional de práticas integrativas e complementares no SUS: Atitude de ampliação de acesso. 2. ed., 1. reimp. Brasília: Ministério da Saúde, Secretaria de Atenção à Saúde, Departamento de Atenção Básica. Recuperado de http://bvsms.saude.gov.br/bvs/publicacoes/politica praticas integrativas complementares sus 2ed 1 reimp.pdf

Oliveira, D. do C., \& Mandú, E. N. T. (2015). Women with high-risk pregnancy: Experiences and perceptions of needs and care. Escola Anna Nery - Revista de Enfermagem, 19(1), 93-101.

Pereira, S. B., Diaz, C. M. G., Backes, M. T. S., Ferreira, C. L. de L., \& Backes, D. S. (2018). Good practices of labor and birth care from the perspective of health professionals. Revista Brasileira de Enfermagem, 71(Suppl. 3), $1313-1319$.

Queirós, P. J. P., Fonseca, E. P. A. M., Mariz, M. A. D., Chaves, M. C. R. F., \& Gómez Cantarino, S. (2016). Significados atribuídos ao conceito de cuidar. Revista de Enfermagem Referência, sér. IV(10), 85-94.

Wosien, B. (2000). Dança: Um caminho para totalidade. São Paulo: Triom.

\footnotetext{
Como citar este artigo:
}

Santos, E. R. da S., Mendonça, G. de A., Souza, Z. C. S. do N., Morais, A. C., \& Novaes, A. L. (2021). Dança circular em maternidade: Vivência extensionista. Revista Brasileira de Extensão Universitária, 12(1), 23-32. https://periodicos.uffs.edu.br/index.php/RBEU/ article/view/11632/pdf 